\title{
Evaluation of Unfavorable Cardiovascular and Metabolic Risk Factors in Children and Young Adults with Haemophilia
}

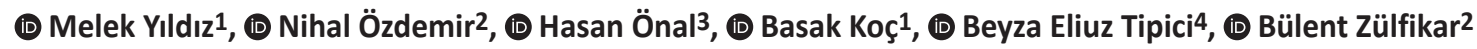 \\ 1istanbul University Cerrahpaşa Faculty of Medicine, Department of Pediatrics, Istanbul, Turkey \\ 2istanbul University Cerrahpaşa Faculty of Medicine and Oncology Institute, Department of Pediatric Hematology and Oncology, Istanbul, Turkey \\ 3istanbul University Cerrahpaşa Faculty of Medicine, Department of Pediatric Metabolism and Nutrition, Istanbul, Turkey \\ 4 istanbul University istanbul Faculty of Medicine, Department of Nutrition and Dietetics, istanbul, Turkey
}

\begin{abstract}
What is already known on this topic?
Patients with haemophilia were reported to have a reduced cardiovascular mortality due to a protective effect of having lifelong deficiency of factor 8 or 9 . However, there is increasing evidence that this condition does not appear to be preventive.
\end{abstract}

\section{What this study adds?}

Cardiovascular and metabolic risk factors like overweight/obesity, elevated blood pressure/hypertension, prediabetes/diabetes and dyslipidaemia can be detected from early ages in patients with haemophilia.

\begin{abstract}
Objective: Increased risk of unfavorable cardiovascular risk factors has been recognised in ageing patients with haemophilia (PwH), but needs further studies in younger patients. The purpose of this study was to assess obesity, hypertension (HT), metabolic variables, insulin resistance and metabolic syndrome in young $\mathrm{PwH}$.

Methods: Forty-eight haemophilia A and B patients and 35 age and sex matched healthy controls were included in the study. Anthropometric measurements, blood pressure (BP), fasting glucose and insulin levels, serum lipids and diet were evaluated. The metabolic syndrome was defined according to the criteria of the International Diabetes Federation for pediatric and adult age groups. Results: The mean age of PwH was $21 \pm 9$ years (range, 6-40 years). Of those $\geq 18$ years, $46 \%$ were were obese/overweight while there were no obese/overweight cases in the $<18$ year-old patients. Obesity was more prevalent in PwH with arthropathy ( $p=0.017)$. Seven percent of the $\mathrm{PwH}$ between 10 and 18 years-old and $25 \%$ of those $\geq 18$ years had metabolic syndrome. There was no difference in metabolic syndrome frequency between PwH and controls $>10$ years-old $(19.5 \%$ vs $10 \%$ respectively, $\mathrm{p}=0.34)$. Fifty percent of the $\mathrm{PwH} \geq 18$ years-old had elevated BP or HT. Fasting blood glucose levels of $\mathrm{PwH}$ were significantly higher compared to controls $(\mathrm{p}=0.02)$.

Conclusion: Our study showed that obesity, HT and metabolic syndrome are frequent problems, especially in PwH with arthropathy. Early prevention and management of overweight, obesity and their sequelae must be addressed in clinical practice in order to maximize the overall health of the haemophilia population.
\end{abstract}

Keywords: Haemophilia, obesity, hypertension, metabolic syndrome

\section{Introduction}

In recent years, cardiovascular and metabolic risk has been defined in the ageing population of haemophiliacs. Studies in this area in young patients with haemophilia $(\mathrm{PwH})$ are scarce $(1,2)$. With increasing life expectancy of heamophilia patients, mortality and risk determination due to cardiovascular diseases has become an issue. While cardiovascular mortality was reported to be reduced in $\mathrm{PwH}$ due to a protective effect of having lifelong deficiency of factor 8 or $9(3,4)$, there is an increasing evidence that this condition does not appear to prevent cardiovascular disease (5). Furthermore, Sun et al (2) recently demonstrated a
Address for Correspondence: Melek Yıldız MD, İstanbul University of Health Sciences, Kanuni Sultan Süleyman Training and Research Hospital, Clinic of Pediatric Endocrinology, İstanbul, Turkey

Phone: + 905057465176 E-mail: melek_erbas@yahoo.com ORCID ID: orcid.org/0000-0002-6603-2983

${ }^{\circ}$ Copyright 2019 by Turkish Pediatric Endocrinology and Diabetes Society

The Journal of Clinical Research in Pediatric Endocrinology published by Galenos Publishing House
Conflict of interest: None declared Received: 11.12 .2018 Accepted: 23.12.2018 
significantly inferior microvascular endothelial function in haemophilia patients compared to healthy controls. Besides atherosclerosis, other established risk factors including obesity, hypertension (HT), dyslipidaemia, diabetes mellitus (DM) and family history for cardiovascular diseases are also known to play a crucial role in mortality and morbidity of these patients (1). Recently, Limjoco and Thornburg (6) studied these risk factors in a young haemophiliac population, aged 5-20 years, and identified modifiable risk factors for cardiovascular diseases.

Severe obesity in children and young adults is known to be associated with an increased prevalence of cardiometabolic risk factors, particularly among boys and young men (7). Haemophilia is characterized by progressive arthropathy, functional impairment and chronic joint pain. These are all barriers towards engagement in physical activity and may limit an individual's ability to maintain a healthy weight $(8,9)$. Therefore, obesity is a health issue in $\mathrm{PwH}$ as well as an aggravating factor for cardiometabolic and joint health (9).

Prevalence of HT in adults with moderate to severe haemophilia has been shown to be increased (10). Alperstein et al (11) reported an increased prevalence of HT in a hospitalized pediatric hemophilia population compared to a pediatric healthy male population, although this was not statistically significant ( $1.52 \%$ vs. $1.22 \%, p=0.26)$. Recently, Limjoco and Thornburg (6) reported high rates of overweight and obesity, (pre) HT and abnormal lipid levels in children and young adults with haemophilia.

The primary aim of this study was to assess obesity, HT, metabolic variables, insulin resistance and metabolic syndrome in children and young adults with haemophilia. We hypothesized that increased risk for cardiometabolic diseases could start from younger ages in $\mathrm{PwH}$.

\section{Methods}

\section{Study Design}

This cross-sectional study was conducted in the Department of Pediatric Hematology and Oncology of Cerrahpaşa Medical Faculty and Oncology Institute of İstanbul University, between February 2010 and November 2010. Forty-eight PwH and 35 age and sex matched healthy controls were included. The study was approved by İstanbul Clinical Research Ethics Committee No:1 (No: C-009/2010). Informed consent was obtained from parents for age groups 6-12 years, from both subjects and parents for age groups 12-18 years, and from subjects only in those older than 18 years, in accordance with the Declaration of Helsinki.

\section{Patients}

During the regular outpatient clinic visit for hemophiliac patients, consecutive patients were asked to participate in the study. Forty-eight male patients, aged 6-40 years, with hemophilia A and B were included in the study irrespective of the severity of their disease. Patients with a coagulation factor level of less than $1 \%$ of normal were classified as severe, 1-5\% of normal were classified as moderate, and $5-40 \%$ of normal were classified as mild (12). The past medical records of the participants were examined. Age of diagnosis, annual spontaneous or traumatic bleeding rate, annual factor consumption, presence of chronic arthropathy, whether physiotherapy or home exercise was undertaken, sports and dietary habits, presence of other systemic diseases and/or other complications of haemophilia, such as carrier status of HBV, HCV, HIV or presence of inhibitor were recorded. Collected data items also included self-reported family history for DM, HT, coronary artery disease (CAD) (male $<55$ years, female $<65$ years) and dyslipidaemia. The annual factor consumption per kilogram of body weight (in international units/kg) was determined for each patient for the 12-month period prior to enrollment. Factors used for elective interventional and surgical procedures were not taken into account. Patients with a history of known cardiovascular disease were not included in the study. Blood samples were taken as part of the clinical follow-up of patients.

\section{Control Group}

The control group consisted of 35 age-matched, random male subjects, with no history of congenital or acquired bleeding disorder, cardiovascular disease or chronic disease, who presented to the outpatient clinics of the pediatric or internal medicine departments. Age, sports and dietary habits, self-reported family history for DM, HT, CAD (male $<55$ years, female < 65 years) and dyslipidaemia were recorded.

Assessment of exercise and nutritional status: In the study and control groups, for individuals under 18 years, at least three days and 30 minutes regular exercise a week; for individuals aged 18 years and older, at least two days and 30 minutes a week were classified as those who perform regular exercise and others were classified as nonperforming.

Dietary intake was evaluated by an experienced dietitian using a 3-day food record. Subjects were given detailed oral and written instructions regarding the completion of a 3-day food record, consisting of two midweek days and one weekend day. In order to determine the amounts of 
consumed foods correctly, information was given about measuring cups such as water glass, tea glass, teaspoon, tablespoon, serving spoon and bowl. Energy and nutrient intake was analyzed by a computerized food analysis program adapted for our country (BeBis4 software program, Turkish version, Stuttgart, Germany) and evaluated according to the recommendations of the Turkish Dietary Guidelines (13). A percentage level of sixty-six or less of the references was used as the criterium for inadequate nutritional intake (14). Over $300 \mathrm{mg}$ daily cholesterol intake was considered as high intake.

Anthropometric measurements: All participants underwent a complete physical examination, including standardized measurement of weight, height and waist circumference, in duplicate. Body mass index (BMI) standard deviation (SD) scores values were calculated for children < 18 years, using Turkish national reference data (15). Subjects with BMI $\geq 95 \%$ were defined as obese and with BMI $\geq 85 \%$ and $<95 \%$ as overweight. BMI was calculated for adults and classified as underweight, normal weight, overweight or obese based on World Health Organization classification (16). Waist circumference was evaluated according to NHANES 3 reference limits appropriate for age and sex (17). Blood pressure (BP) was evaluated by three consecutive measurements. In children < 13 years of age, HT was defined as systolic or diastolic BP $\geq 95^{\text {th }}$ percentile according to the recent sex, age and height tables (18). For adolescents $\geq 13$ years and adults, HT was defined as systolic and/or diastolic BP $\geq 140 / 90 \mathrm{mmHg}$ and elevated BP was defined as systolic and/or diastolic BP $\geq 120 / 80 \mathrm{mmHg}$ according to 2017 guidelines $(18,19)$.

Biochemical assessment: In all subjects, fasting glucose, total cholesterol, low-density lipoprotein-cholesterol, highdensity lipoprotein-cholesterol, triglyceride, uric acid (measured by enzymatic colorimetric method using Abbott Architect c8000 autoanalyzer) and insulin (measured with chemiluminescence, by Abbott Architect i2000) levels were evaluated. Hyperglycemia was defined as a fasting glucose level of $\geq 100 \mathrm{mg} / \mathrm{dL}$. Insulin resistance was estimated by the Homeostasis Model Assessment of Insulin Resistance (HOMA-IR) formula, that is fasting serum insulin $(\mu \mathrm{U} / \mathrm{mL})$ $x$ fasting plasma glucose $(\mathrm{mmol} / \mathrm{L}) / 22.5$, as described by Matthews et al (20). For adults, a HOMA-IR value above 2.7 was considered as insulin resistance (21). For children and adolescents, insulin resistance was evaluated by HOMA-IR values higher than $\geq 97^{\text {th }}$ percentile for age and sex (22).

The criteria of the International Diabetes Federation, in children above 10 years (23) and adults (24) were used for assessment of metabolic syndrome.

\section{Statistical Analysis}

The data were analyzed using the Statistical Package for Social Sciences program, version 18.0 (IBM Inc., Chicago, IL, USA). For baseline characteristics, a descriptive statistical analysis was performed using percentages for categorical variables, mean \pm SD for normally distributed continuous variables and median (range) for skewed continuous variables. Differences between two groups were tested using two-sample t-test or Mann-Whitney $U$ test for continuous variables and chi-square test or Fisher's exact test for categorical variables, as appropriate. Results were evaluated at $95 \%$ confidence interval and a p value less than 0.05 was considered statistically significant.

\section{Results}

A total of 48 haemophilia patients and 35 age and sex matched healthy controls were included in the analysis. The demographic characteristics between the groups were similar. Mean ages of the haemophilia and control groups were $20.5 \pm 9.1$ years and $21.4 \pm 9.0$ years, respectively $(p=0.65)$. There was no difference in weight, height, BMI and waist circumference values of $\mathrm{PwH}$ and controls (Table 1). Median age at diagnosis was 11 (1-129) months among haemophilia patients. Sixty-six percent of haemophilia A and $50 \%$ of haemophilia B patients were on prophylaxis, others were on demand therapy. Median annual factor consumption for haemophilia $A$ and $B$ patients were $1846 \mathrm{IU} / \mathrm{kg}$ (0-3600) and $840 \mathrm{IU} / \mathrm{kg}$ (3182434), respectively. The frequency of $\mathrm{PwH}$ with inhibitors was $8.3 \%$ and these subjects were mainly severe type haemophilia A cases. Arthropathy was present in $61.9 \%$ of the haemophilia A and $66.7 \%$ of haemophilia B patients; and mainly in patients of severe type over 18 years old. Only a few of the patients were getting physiotherapy (5\% of haemophilia A and none of the haemophilia B patients).

Energy, protein, fat, carbohydrate, fiber and cholesterol intakes by age and sex were calculated in the haemophilia and control groups according to their food consumption records (Table 1). Energy intake was significantly higher in the control group $(p=0.02)$, but other nutrient intakes were similar. Subjects in both study and control groups were exposed to similar amounts of regular exercise. Haemophilia patients of normal weight were taking less regular exercise compared to those with overweight or obesity, $14.3 \%$ of the normal weight group compared to $23.1 \%$ of the overweight/ obese patients although this was not significant $(p=0.66)$.

Biochemical assessment of all participants is shown in Table 2. Fasting blood glucose levels of $\mathrm{PwH}$ were higher 
compared to controls $(p=0.02)$. However, serum triglyceride concentrations were significantly lower in the haemophilia group ( $p=0.008$ ). Total cholesterol levels were somewhat lower in the haemophilia group, but the difference did not reach statistical significance. Forty-six percent of $\mathrm{PwH}$ over 18 years were overweight/obese, however none of the patients younger than 18 years old were overweight/ obese. Obesity was more prevalent in $\mathrm{PwH}$ with arthropathy $(p=0.017)$. When metabolic syndrome was assessed in different age groups, none of the patients $<10$ years old had metabolic syndrome, $7.7 \%$ of patients between 10 and 18 years old and $25 \%$ of $\mathrm{PwH}$ between 18 and 40 years old had metabolic syndrome. Fifty percent of PwH
$>18$ years had elevated BP/HT vs $23 \%$ of those $\leq 18$ years $(p=0.03)$. The frequency of elevated BP/HT remained higher in all subjects in the haemophilia cohort, although not statistically significant, when compared to controls (35.5\% vs. 28.6\%, p=0.51). When $\mathrm{PwH}$ and controls over 10 years were compared for metabolic syndrome, no statistically significant difference was found $(19.5 \%$ and $10 \%$ respectively, $p=0.34$ ). Comparison of metabolic variables among haemophilia patients and controls are shown in Table 3. In addition, the Spearman correlation analysis did not show any correlation between annual factor consumption and any of the metabolic parameters in $\mathrm{PwH}$.

\begin{tabular}{|c|c|c|c|}
\hline & Haemophilia patients $(n=48)(\%)$ & Controls $(n=35)(\%)$ & $\mathrm{p}$ value \\
\hline Number of subjects by age groups & & & 0.99 \\
\hline 6-9.9 years & $7(14.6 \%)$ & $5(14.3 \%)$ & \\
\hline $10-17.9$ years & $13(27.1 \%)$ & $9(25.7 \%)$ & \\
\hline $18-40$ years & $28(58.3 \%)$ & $21(60.0 \%)$ & \\
\hline Children ( $<18$ years) & $(\mathrm{n}=20)$ & $(n=14)$ & \\
\hline Weight (SDS) & $0.1(-2.7-2.4)$ & $-0.1(-2.7-1.6)$ & 0.29 \\
\hline Height (SDS) & $0.1(-2.1-2.4)$ & $-0.1(-1.5-1.3)$ & 0.56 \\
\hline BMI (SDS) & $-0.1(-2.9-1.8)$ & $-0.6(-2.7-1.4)$ & 0.28 \\
\hline Adults ( $\geq 18$ years) & $(n=28)$ & $(\mathrm{n}=21)$ & \\
\hline Weight (kg) & $74(52-95)$ & $81(55-105)$ & 0.06 \\
\hline Height $(\mathrm{cm})$ & $175(166-187)$ & $175(158-190)$ & 0.63 \\
\hline BMI (kg/m²) & $24.0(17.9-30.0)$ & $25.1(18.8-30.0)$ & 0.10 \\
\hline Waist circumference $(\mathrm{cm})$ & $89(70-111)$ & $92(71-106)$ & 0.27 \\
\hline Exposure to regular exercise & $8(16.7 \%)$ & $6(17.1 \%)$ & 0.95 \\
\hline \multicolumn{4}{|l|}{ Energy and nutrient intakes } \\
\hline Energy (kcal) & $1318(496-2530)$ & $1572(900-2573)$ & 0.02 \\
\hline Protein (\%) & $15.9 \pm 2.8$ & $16.7 \pm 3.3$ & 0.29 \\
\hline Lipid (\%) & $36.1 \pm 5.2$ & $35.4 \pm 3.7$ & 0.51 \\
\hline Carbohydrate (\%) & $48.1 \pm 6.3$ & $47.8 \pm 4.5$ & 0.80 \\
\hline Fiber (gr) & $12.7(5.9-27.0)$ & $15.2(6.5-23.5)$ & 0.06 \\
\hline Cholesterol (mg) & $176.0(18.7-378.7)$ & $178.0(81.3-365.7)$ & 0.18 \\
\hline \multicolumn{4}{|l|}{ Haemophilia type } \\
\hline A (\%) & $42(87.5 \%)$ & N/A & N/A \\
\hline $\mathrm{B}(\%)$ & $6(12.5 \%)$ & N/A & N/A \\
\hline \multicolumn{4}{|l|}{ Haemophilia severity } \\
\hline Mild & $4(8.3 \%)$ & N/A & N/A \\
\hline Moderate & $2(4.2 \%)$ & N/A & N/A \\
\hline Severe & $42(87.5 \%)$ & N/A & N/A \\
\hline Arthropathy & $30(62.5 \%)$ & N/A & N/A \\
\hline Annual factor consumption (IU/kg) & $1796(0-3600)$ & N/A & N/A \\
\hline
\end{tabular}




\begin{tabular}{|c|c|c|c|}
\hline & Haemophilia patients $(n=48)$ & Controls $(n=35)$ & $\mathrm{p}$ value \\
\hline Fasting glucose (mg/dL) & $93.9 \pm 9.9$ & $88.1 \pm 12.5$ & 0.02 \\
\hline HOMA-IR & $1.8(0.7-5.5)$ & $1.7(0.2-8.3)$ & 0.32 \\
\hline Total cholesterol (mg/dL) & $153.2 \pm 36.9$ & $165.1 \pm 32.6$ & 0.13 \\
\hline Triglyceride (mg/dL) & $66.5(31-261)$ & $93(42-372)$ & 0.008 \\
\hline Uric acid (mg/dL) & $5.0 \pm 1.3$ & $5.4 \pm 1.5$ & 0.23 \\
\hline
\end{tabular}

Data are presented as mean \pm standard deviation, median (range).

HOMA-IR: homeostasis model assessment of insulin resistance, LDL: low-density lipoprotein, HDL: high-density lipoprotein

Table 3. Frequency of metabolic syndrome components

\begin{tabular}{llll}
\hline & Haemophilia patients $(\mathrm{n}=48)$ & Controls $(\mathrm{n}=35)$ & $\mathrm{p}$ value \\
\hline Overweight/obese & $13(27.1 \%)$ & $11(31.5 \%)$ & 0.66 \\
Central obesity* & $3(6.3 \%)$ & $3(8.6 \%)$ & 0.68 \\
Elevated BP/HT & $17(35.5 \%)$ & $10(28.6 \%)$ & 0.51 \\
Dyslipidaemia & & & 0.28 \\
Hypertriglyceridemia & $5(10.4 \%)$ & $6(17.1 \%)$ & 0.35 \\
Low HDL-cholesterol & $2(4.2 \%)$ & $3(8.6 \%)$ & 0.33 \\
Insulin resistance & $11(22.9 \%)$ & $5(14.3 \%)$ & 0.02 \\
Hyperglycemia & $14(29.2 \%)$ & $3(8.6 \%)$ & 0.88 \\
Family history of CVD & $28(58.3 \%)$ & $21(60.0 \%)$ & \\
\hline
\end{tabular}

*According to waist circumference.

BP: blood pressure, HT: hypertension, CVD: cardiovascular disease, HDL: high-density lipoprotein

\section{Discussion}

Our study showed that obesity, HT and metabolic syndrome are frequent problems in $\mathrm{PwH}$, especially in those over 18 years with arthropathy. Early prevention and management of overweight, obesity and their sequelae must be addressed in clinical practice in order to maximize the overall health of the haemophilia population. Therefore, assessment of cardiovascular and metabolic risk factors, beginning from early childhood, is crucial for this specific patient population.

The relationship between haemophilia and cardiovascular risk is not yet well understood (25). In several cohort studies Haemophilia has traditionally been regarded as a protective state for thrombosis due to hypocoagulability $(3,4)$. However, some studies indicated a potential negative effect of haemophilia (26), while some found no substantial effect (27). As obesity is an important risk factor for cardiovascular disease, the impact of obesity in the haemophilia population on cardiovascular disease has been reviewed (9). These authors recommended implementing general guidelines for weight management in the context of the haemophilia care team.

Overall life expectancy and quality of life among the haemophiliac population have increased in recent years, primarily because of the reduction in mortality/morbidity due to infections and advances in factor replacement therapy. However, older patients who had been treated with on demand therapy still have a variety of orthopedic problems. In our study, overweight and obesity were frequent in subjects over 18 years with target joints. This finding may be attributed to reduced engagement in physical activity to prevent bleeding and to protect the joints. Besides, target joints progressively lead to pain, restriction of movement and potentially irreversible structural damage, the hallmarks of haemophilic arthropathy. The associated reduced physical activity results in weight gain. Furthermore, the reduced mobility and loss of muscle function leads to muscle atrophy, which may in turn increase the risk of weight gain (28). Furthermore, in a Dutch haemophilia cohort, it has been reported that overweight/obesity itself increased the number of joint bleeds and reduced function in the lower 
limbs (29). Recently, Limjoco and Thornburg (6) reported high rates of overweight and obesity in a relatively younger haemophilia cohort (mean age 12 years, range 5-20 years). However, these authors identified no difference in target joints based on weight category (30\% in normal weight vs. $25 \%$ in overweight or obese, $p=0.74$ ). They suggested that the impact of overweight and obesity on joint disease may have been offset by the high rate of prophylaxis or that it may manifest over longer periods of time in follow-up.

Another outcome of increase in life expectancy of $\mathrm{PwH}$ is experiencing cardiovascular complications. HT is one of the most relevant cardiovascular risk factors that has gained attention, since it is also a major risk factor for intracranial hemorrhage in $\mathrm{PwH}$ (30). There are some studies documenting an increased rate of $\mathrm{HT}$ in adults with hemophilia $(10,31)$ but little is currently known about its prevalence and severity. Increased prevalence of HT may be the result of the regular visits of these patients to clinics and getting the diagnosis of HT or due to intraparenchymal hemorrhages in the kidneys (32). Recently, a slightly increased prevalence of HT was reported in a pediatric hemophilia population, thus raising awareness of the need for assessment of BP even in young PwH (11). Our study showed that the prevalence of elevated BP and HT was higher, especially in $\mathrm{PwH}$ over 18 years, although this finding was not statistically significant. Nevertheless, the clinical difference noted in the hemophiliac group demonstrates a trend and warrants further study. BP measurements should be a part of standard care in $\mathrm{PwH}$ early in their life, with the possible consideration of early intervention.

Although none of the patients had DM in our cohort, higher concentrations of fasting blood glucose, which predicts diabetes, were observed. The same subpopulation was affected by both increased blood glucose levels and obesity, as expected. Biere-Rafi et al (1) identified a higher proprotion of $\mathrm{PwH}$ with hyperglycemia than controls. In contrast Alperstein et al (11) reported a low prevalence of DM in a pediatric haemophilia population. While the prevalence of dyslipidaemia was similar among haemophiliacs and the control group, mean serum concentrations of triglyceride were significantly lower in our haemophilia group. Additional research is required to determine whether blood glucose and lipid screening should start earlier for children with haemophilia.

The frequency of metabolic syndrome in our pediatric $\mathrm{PwH}$ (aged 10-18 years) was higher than Turkish data on healthy schoolchildren, aged 10-19 years, according to the criteria of IDF ( $7.7 \%$ vs $2.3 \%$, respectively) (33). However, for the adult age group of $\mathrm{PwH}$, frequency of metabolic syndrome was comparable with previously reported data ( $25 \%$ in $\mathrm{PwH}$ vs. $31.2 \%$ in Turkish adult males) (34).

\section{Study Limitations}

This study has several limitations. Our haemophilia patients were very heterogeneous with a wide age range (child, adolescent and adult), with both haemophilia $A$ and $B$ and all degrees of severity. Therefore, most of the subgroup analyses could not be performed and the relationship between cardiometabolic risk factors and severity of disease could not be analyzed. Further studies should include a more homogenous study population. Furthermore, our data were collected from past medical records and at only one outpatient clinic visit rather than over time. Repeated BP measurements on different days are needed for the accurate estimation and diagnosis of HT, and the exclusion of "white coat" HT. Although we were not able to collect measurements on different days, we referred all subjects with at least one episode of elevated BP/HT for further assessment. Another limitation of our study was that we did not have information about smoking and alcohol use, which will have an impact on cardiovascular and metabolic parameters. Furthermore, we asked about the subject's routine exercise status, but did not question them about how many hours they spend watching TV, playing computer games and using mobile phones, which are risk factors for the development of obesity. Further studies should be designed to follow-up patients longitudinally.

\section{Conclusion}

In conclusion, cardiovascular and metabolic risk factors like overweight/obesity, elevated $\mathrm{BP} / \mathrm{HT}$, prediabetes/DM and dyslipidaemia can be detected from very early ages in $\mathrm{PwH}$. Screening from early ages for cardiovascular risk factors and considering early intervention and management might help to improve the general health status of this specific patient group and reduce morbidity.

\section{Ethics}

Ethics Committee Approval: The study was approved by İstanbul Clinical Research Ethics Committee No: 1 (No: C-009/2010).

Informed Consent: Informed consent was obtained from parents for ages 6-12 years, from both subjects and parents for age of 12-18 years, and from subjects of ages older than 18 years, in accordance with the Declaration of Helsinki.

Peer-review: Externally and internally peer-reviewed. 


\section{Authorship Contributions}

Concept: Melek Yıldız, Bülent Zülfikar, Hasan Önal, Data Collection or Processing: Melek Yıldız, Nihal Özdemir, Beyza Eliuz Tipici, Bülent Zülfikar, Analysis or Interpretation: Melek Yıldız, Nihal Özdemir, Beyza Eliuz Tipici, Hasan Önal, Literature Search: Melek Yıldız, Nihal Özdemir, Başak Koç, Writing: Melek Yıldız, Başak Koç, Nihal Özdemir.

Financial Disclosure: This research was supported by the research grant from Haemophilia Society of Turkey. Project No: 292/173.

\section{References}

1. Biere-Rafi S, Baarslag MA, Peters M, Kruip MJ, Kraaijenhagen RA, Den Heijer M, Büller HR, Kamphuisen PW. Cardiovascular risk assessment in haemophilia patients. Thromb Haemost 2011;105:274-278. Epub 2010 Dec 6

2. Sun $\mathrm{H}$, Yang M, Fung M, Chan S, Jawi M, Anderson T, Poon MC, Jackson S. Adult males with haemophilia have a different macrovascular and microvascular endothelial function profile compared with healthy controls. Haemophilia 2017;23:777-783. Epub 2017 Jun 16

3. Rosendaal FR, Varekamp I, Smit C, Brocker-Vriends AH, van Dijck H, Vandenbroucke JP, Hermans J, Suurmeijer TP, Briët E. Mortality and causes of death in Dutch haemophiliacs, 1973-86. Br J Haematol 1989;71:71-76

4. Darby SC, Kan SW, Spooner RJ, Giangrande PL, Hill FG, Hay CR, e Lee CA, Ludlam CA, Williams M. Mortality rates, life expectancy, and causes of death in people with hemophilia A or B in the United Kingdom who were not infected with HIV. Blood 2007;110:815-825. Epub 2007 Apr 19

5. Biere-Rafi S, Tuinenburg A, Haak BW, Peters M, Huijgen R, De Groot E, Verhamme P, Peerlinck K, Visseren FL, Kruip MJ, Laros-Van Gorkom BA, Gerdes VE, Buller HR, Schutgens RE, Kamphuisen PW. Factor VIII deficiency does not protect against atherosclerosis. J Thromb Haemost 2012;10:30-37

6. Limjoco J, Thornburg CD. Risk factors for cardiovascular disease in children and young adults with haemophilia. Haemophilia 2018;24:747-754. Epub 2018 Jul 13

7. Skinner AC, Perrin EM, Moss LA, Skelton JA. Cardiometabolic Risks and Severity of Obesity in Children and Young Adults. N Engl J Med 2015;373:1307-1317.

8. Roosendaal G, Lafeber FP. Pathogenesis of haemophilic arthropathy Haemophilia 2006;12(Suppl 3):117-121

9. Kahan S, Cuker A, Kushner RF, Maahs J, Recht M, Wadden T, Willis T, Majumdar S, Ungar D, Cooper D. Prevalence and impact of obesity in people with haemophilia: Review of literature and expert discussion around implementing weight management guidelines. Haemophilia 2017;23:812-820. Epub 2017 Jun 21

10. von Drygalski A, Kolaitis NA, Bettencourt R, Bergstrom J, KruseJarres R, Quon DV, Wassel C, Li MC, Waalen J, Elias DJ, Mosnier LO, Allison M. Prevalence and risk factors for hypertension in hemophilia. Hypertension 2013;62:209-215. Epub 2013 Apr 29

11. Alperstein W, Corrales-Medina FF, Tamariz L, Palacio AM, Davis JA. Prevalence of Hypertension (HTN) and Cardiovascular Risk Factors in a Hospitalized Pediatric Hemophilia Population. J Pediatr Hematol Oncol 2018;40:196-199.

12. White GC, Rosendaal F, Aledort LM, Lusher JM, Rothschild C, Ingerslev J; Factor VIII and Factor IX Subcommittee. Definitions in hemophilia.
Recommendation of the scientific subcommittee on factor VIII and factor IX of the scientific and standardization committee of the International Society on Thrombosis and Haemostasis. Thromb Haemost 2001;85:560.

13. Turkey Dietary Guidelines. Ankara: Ministry of Turkey Health; 2016. Available from: https://dosyasb.saglik.gov.tr/ Eklenti/10922,17ocaktuberingilizcepdf.pdf?0

14. Trumbo P, Schlicker S, Yates AA, Poos M; Food and Nutrition Board of the Institute of Medicine, The National Academies. Dietary reference intakes for energy, carbohydrate, fiber, fat, fatty acids, cholesterol, protein and amino acids. J Am Diet Assoc 2002;102:1621-1630.

15. Bundak R, Furman A, Gunoz H, Darendeliler F, Bas F, Neyzi O. Body mass index references for Turkish children. Acta Paediatr 2006;95:194198.

16. WHO Expert Consultation. Appropriate body-mass index for Asian populations and its implications for policy and intervention strategies. Lancet 2004;363:157-163.

17. Hickman TB, Briefel RR, Carroll MD, Rifkind BM, Cleeman JI, Maurer $\mathrm{KR}$, Johnson CL. Distributions and trends of serum lipid levels among United States children and adolescents ages 4-19 years: data from the Third National Health and Nutrition Examination Survey. Prev Med 1998;27:879-890

18. Flynn JT, Falkner BE. New Clinical Practice Guideline for the Management of High Blood Pressure in Children and Adolescents. Hypertension 2017;70:683-686. Epub 2017 Aug 21

19. Whelton PK, Carey RM, Aronow WS, Casey DE Jr, Collins KJ, Dennison Himmelfarb C, DePalma SM, Gidding S, Jamerson KA, Jones DW, MacLaughlin EJ, Muntner P, Ovbiagele B, Smith SC Jr, Spencer CC, Stafford RS, Taler SJ, Thomas RJ, Williams KA Sr, Williamson JD, Wright JT Jr. 2017 ACC/AHA/AAPA/ABC/ACPM/AGS/APhA/ASH/ASPC/ NMA/PCNA Guideline for the Prevention, Detection, Evaluation, and Management of High Blood Pressure in Adults: Executive Summary: A Report of the American College of Cardiology/American Heart Association Task Force on Clinical Practice Guidelines. Hypertension 2018;71:1269-1324. Epub 2017 Nov 13

20. Matthews DR, Hosker JP, Rudenski AS, Naylor BA, Treacher DF, Turner RC. Homeostasis model assessment: insulin resistance and beta-cell function from fasting plasma glucose and insulin concentrations in man. Diabetologia 1985;28:412-419.

21. Bonora E, Kiechl S, Willeit J, Oberhollenzer F, Egger G, Targher G, Alberiche M, Bonadonna RC, Muggeo M. Prevalence of insulin resistance in metabolic disorders: the Bruneck Study. Diabetes 1998;47:1643-1649

22. Shashaj B, Luciano R, Contoli B, Morino GS, Spreghini MR, Rustico C, Sforza RW, Dallapiccola B, Manco M. Reference ranges of HOMAIR in normal-weight and obese young Caucasians. Acta Diabetol 2016;53:251-260. Epub 2015 Jun 13

23. Zimmet P, Alberti KG, Kaufman F, Tajima N, Silink M, Arslanian S, Wong G, Bennett P, Shaw J, Caprio S; IDF Consensus Group. The metabolic syndrome in children and adolescents - an IDF consensus report. Pediatr Diabetes 2007;8:299-306.

24. Eckel RH, Grundy SM, Zimmet PZ. The metabolic syndrome. Lancet 2005:365:1415-1428

25. Sousos N, Gavriilaki E, Vakalopoulou S, Garipidou V. Understanding cardiovascular risk in hemophilia: A step towards prevention and management. Thromb Res 2016;140:14-21. Epub 2016 Feb 2

26. Pocoski J, Ma A, Kessler CM, Boklage S, Humphries TJ. Cardiovascular comorbidities are increased in U.S. patients with haemophilia A: a retrospective database analysis. Haemophilia 2014;20:472-478. Epub 2013 Nov 29 
27. Wang JD, Chan WC, Fu YC, Tong KM, Chang ST, Hwang WL, Lin CH, Tsan YT. Prevalence and risk factors of atherothrombotic events among 1054 hemophilia patients: a population-based analysis. Thromb Res 2015;135:502-507. Epub 2015 Jan 10

28. Wilding J, Zourikian N, Di Minno M, Khair K, Marquardt N, Benson G, Ozelo M, Hermans C. Obesity in the global haemophilia population: prevalence, implications and expert opinions for weight management. Obes Rev 2018;19:1569-1584. Epub 2018 Sep 6

29. Biere-Rafi S, Haak BW, Peters M, Gerdes VE, Büller HR, Kamphuisen PW. The impairment in daily life of obese haemophiliacs. Haemophilia 2011;17:204-208

30. Sharathkumar AA, Soucie JM, Trawinski B, Greist A, Shapiro AD. Prevalence and risk factors of cardiovascular disease (CVD) events among patients with haemophilia: experience of a single haemophilia treatment centre in the United States (US). Haemophilia 2011;17:597604. Epub 2011 Feb 15

31. Rosendaal FR, Briet E, Stibbe J, van Herpen G, Leuven JA, Hofman A, Vandenbroucke JP. Haemophilia protects against ischaemic heart disease: a study of risk factors. Br J Haematol 1990;75:525-530.

32. Funston MR, Levine E, Stables DP. Spontaneous renal hemorrhage. Urology 1976;8:610-617.

33. Bereket A, Atay Z. Current status of childhood obesity and its associated morbidities in Turkey. J Clin Res Pediatr Endocrinol 2012;4:1-7.

34. Gündogan K, Bayram F, Capak M, Tanriverdi F, Karaman A, Ozturk A, Altunbas H, Gökce C, Kalkan A, Yazici C. Prevalence of metabolic syndrome in the Mediterranean region of Turkey: evaluation of hypertension, diabetes mellitus, obesity, and dyslipidemia. Metab Syndr Relat Disord 2009;7:427-434. 